\title{
Numerical Derivation of Iso-Damaged Curve for a Reinforced Concrete Beam Subjected to Blast Loading
}

\author{
Yehya Temsah $^{1}$, Ali Jahami ${ }^{1}$, Jamal Khatib ${ }^{1,2}$, M Sonebi $^{3}$ \\ ${ }^{1}$ Faculty of Engineering, Beirut Arab University, Beirut, Lebanon \\ ${ }^{2}$ Faculty of Science and Engineering, University of Wolverhampton, Wolverhampton, UK \\ ${ }^{3}$ School of Natural and Built Environment, Queens University of Belfast, Belfast, UK
}

Email: j.khatib@bau.edu.lb

\begin{abstract}
Many engineering facilities are severely damaged by blast loading. Therefore, many manufacturers of sensitive, breakable, and deformed structures (such as facades of glass buildings) carry out studies and set standards for these installations to withstand shock waves caused by explosions. Structural engineers also use these standards in their designs for various structural elements by following the ISO Damage Carve, which links pressure and Impulse. As all the points below this curve means that the structure is safe and will not exceed the degree of damage based on the various assumptions made. This research aims to derive the IsoDamage curve of a reinforced concrete beam exposed to blast wave. An advanced volumetric finite element program (ABAQUS) will be used to perform the derivation.
\end{abstract}

\section{Introduction}

The damage caused by an explosion has been studied after World War 2 by different researchers who derived many formulas. One of the most important formulas used in explosion analysis are the Gurney ${ }^{\mathbf{1}}$ Equations. They help in calculating the velocity of fragments released during an explosion, and this velocity can help the experts to predict the damage level of the explosion and the fragment penetration of structures.

Cylindrical Charge Equation:

$$
\frac{V}{\sqrt{2 E}}-\left(\left(\frac{M}{C}\right)+0.5\right)^{-0.5}
$$

\section{Spherical Charge Equation}

$$
\frac{V}{\sqrt{2 E}}=\left(\left(\frac{M}{C}\right)+0.6\right)^{-0.5}
$$

Where:

$\mathrm{V}=$ Initial Velocity of Fragment $(\mathrm{m} / \mathrm{s})$

$\sqrt{ } 2 \mathrm{E}=$ Gurney Constant for a given blasting materials $(\mathrm{m} / \mathrm{s})$

$\mathrm{M}_{\mathrm{f}}=$ Fragment Mass $(\mathrm{kg})$
$\mathbf{M}_{\mathrm{e}}=$ Blasting materials Charge Mass $(\mathrm{kg})$

Table 1 shows us some of Gurney Constant values $(\sqrt{2} \mathrm{E})$ :

\begin{tabular}{|c|c|c|c|}
\hline $\begin{array}{c}\text { Blasting } \\
\text { Materials }\end{array}$ & $\begin{array}{c}\text { Density } \\
\left(\mathrm{Kg} / \mathrm{m}^{3}\right)\end{array}$ & $\begin{array}{c}\text { Detonation } \\
\text { velocity } \\
(\mathrm{m} / \mathrm{s})\end{array}$ & $\begin{array}{c}\text { Gurney constant } \\
(\mathrm{m} / \mathrm{s})\end{array}$ \\
\hline Comp-B & 1.61 & 7,620 & 2,774 \\
\hline Comp-C4 & 1.71 & 8,200 & 2,530 \\
\hline HMX & 1.91 & 9,100 & 2,972 \\
\hline Octal $75 / 25$ & 1.81 & 8.640 & 2,896 \\
\hline PETN & 1.78 & 8,260 & 2,926 \\
\hline RDX & 1.81 & 8,700 & 2,926 \\
\hline $\begin{array}{c}\text { RDX/TNT } \\
60 / 40\end{array}$ & 1.68 & 7,800 & 2,402 \\
$($ Cyclotol $)$ & 1.71 & 7,570 & 2,499 \\
\hline Tetryl & 1.61 & 6,900 & 2,438 \\
\hline TNT & 1.70 & 5,480 & 2,316 \\
\hline Tritonal & & &
\end{tabular}

Table 1.typical values of Gurney constant (Gurney 1943) ${ }^{1}$

Also it's an important to know the range of damage caused by an explosion so we can consider the appropriate steps for safety. The following equations are used to estimate the safety distance required to avoid the 
fragments effect. These equations are very efficient in the preliminary design stage since they are easy to use.

When using fragmenting munitions and the demolition area is accessible by public:

$$
\mathrm{D}=634(\mathrm{~W})^{1 / 6}
$$

When using fragmenting munitions and the demolition area is not accessible by public:

$$
\mathrm{D}=444(\mathrm{~W})^{1 / 6}
$$

For blasting materials without fragments:

$$
\mathrm{D}=130(\mathrm{~W})^{1 / 3}
$$

Where:

$\mathrm{D}=$ Distance from explosion $(\mathrm{m})$

$\mathrm{W}=$ Total weight of blasting materials $(\mathrm{kg})$

The vertical danger zone limit is very important for planes flying above blast affected zones. It gives us an indication about the minimum required height to fly in order to avoid the explosion impact.

For single ammunition item only:

$$
\mathrm{D}=314(\mathrm{~W})^{1 / 3}
$$

For multi-item fragmenting munitions:

$$
\mathrm{D}=470(\mathrm{~W})^{1 / 5}
$$

Experts are collecting data about explosions and its effect on buildings since World War 2. They used to link the damage level to the standoff distance and the weight of explosion. Many numerical models were derived in the 20th century. One of the most important formulas to estimate the range of damage is illustrated in Equation 8:

$\mathrm{R}_{\mathrm{x}}=\left(\mathrm{K}_{\mathrm{x}} \cdot \mathrm{M}_{\exp }^{1 / 3}\right) /\left(1+\left(3175 / \mathrm{M}_{\mathrm{exp}}\right)^{2}\right)^{1 / 6}$

Where:

$\mathrm{R}_{\mathrm{x}}=$ Range for Damage $(\mathrm{m})$

$\mathrm{K}_{\mathrm{x}}=$ Damage Level Constant

$\mathrm{M}_{\mathrm{exp}}=$ Mass of Blasting materials $(\mathrm{kg})$

Values for $\mathrm{K}_{\mathrm{x}}$ can be obtained from Jarrett and Gilbert ${ }^{2}$, Lees and Scilly ${ }^{3}$. The revised values consider the degree of energy imparted to the primary fragments from the casing which will reduce the air blast energy available.

\begin{tabular}{|c|c|c|}
\hline $\begin{array}{c}\mathrm{K}_{\mathrm{x}} \text { for Damage } \\
\text { Category }\end{array}$ & Jarrett & Gilbert, Lees and Scilly \\
\hline $\mathrm{A}$ & 3.8 & 4.8 \\
\hline $\mathrm{B}$ & 5.6 & 7.1 \\
\hline $\mathrm{C}_{\mathrm{B}}$ & 9.6 & 12.4 \\
\hline$C_{\mathrm{A}}$ & 28.0 & 21.3 \\
\hline$D$ & 56.0 & 42.6 \\
\hline
\end{tabular}

Table 2. $\mathrm{K}_{\mathrm{x}}$ factors (Jarrett 1968) ${ }^{2}$

\begin{tabular}{|c|l|}
\hline Category & \multicolumn{1}{c|}{ Definition } \\
\hline A & Houses completely demolished. \\
\hline B & $\begin{array}{l}\text { Houses so badly damaged they are } \\
\text { beyond repair and require demolition. }\end{array}$ \\
\hline C $_{B}$ & $\begin{array}{l}\text { Houses rendered uninhabitable but can } \\
\text { be repaired with extensive work. }\end{array}$ \\
\hline C $_{A}$ & $\begin{array}{l}\text { Houses rendered uninhabitable but can } \\
\text { be repaired reasonably quickly. }\end{array}$ \\
\hline D & $\begin{array}{l}\text { Houses requiring repairs to remedy } \\
\text { serious inconvenience but remain } \\
\text { habitable. }\end{array}$ \\
\hline
\end{tabular}

Table 3. Damage category (Jarrett 1968) ${ }^{2}$

\section{Aim and scope of the research}

The aim of this research is to derive the Iso-Damage curve for a reinforced concrete beam exposed to an impact load from an explosion using finite element modeling. The data will be collected from an experimental work done by a Chinese researcher as will be illustrated in the coming sections.

\section{Iso-Damage concepts}

Assume that we have a structure which is subjected to a quasi-static load pulse. In the elastic range the work done on the system is converted into strain energy. If this work causes a maximum displacement of $X_{\max }$, then:

$$
\text { Total work done }=\mathrm{FX}
$$

And the strain energy " $U$ " is:

$$
U=K\left(X_{\max }\right)^{2} / 2
$$

Since the total work is converted into strain energy, then we can conclude the quasi-static asymptote as:

$$
\text { Quasi }- \text { staic asymptote }=\frac{\text { Strain Znergy }}{\text { Max dippiacemen: }}
$$

If the load is of short duration, then from the momentum equation it produces an instantaneous velocity change:

$$
v=\frac{I \text { (Impulse) }}{M(\text { Mass })}
$$

As a result, the structure gains kinetic energy given by:

$$
K E=\frac{M v^{2}}{2}=\frac{t^{2}}{2 M}
$$

Then the Impulsive asymptote is:

$$
I c=\sqrt{2 \cdot K E \cdot M}
$$




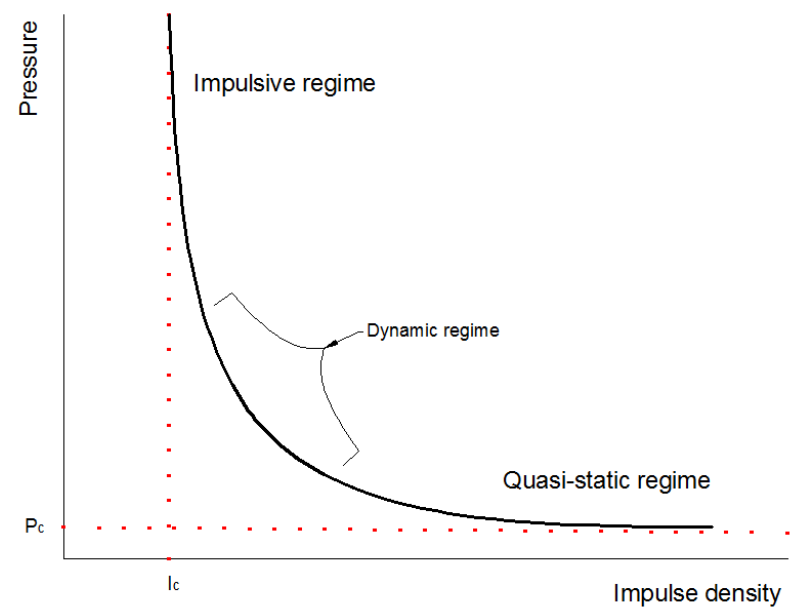

Figure 1. Typical Iso-Damage Curve

\section{Data Collection}

According to the experiment that was done by Zhang et al (2013) ${ }^{4}$ at at the National University of Defense Technology in China, there are 3 sizes of reinforced concrete beams with dimensional ratio of $3: 4: 5$. The dimensions are (850mmx75mmx75mm), (1100mmx100mmx100mm) and $(1350 \mathrm{~mm} \times 125 \mathrm{~mm} \times 125 \mathrm{~mm})$. The bars used for tensile, compressive and hoop reinforcement had a diameter of $6 \mathrm{~mm}$. The spacing between hoops was $6 \mathrm{~mm}$. The number and dimensions of beams are listed in Table 4. The design compressive strength of concrete is $40 \mathrm{MPa}$ whereas the yield strength and ultimate strength of reinforcement steel are $395 \mathrm{MPa}$ and $501 \mathrm{MPa}$ respectively. The blast loading was positioned at the top of the beam and is compressed to a cakey cylinder suspended over the middle of the reinforced concrete (RC) beam, and is ignited by an electronic detonator. The beam is supported using a steel frame as shown in Figure 2. The mid span displacement of the beam is measured using steel needles can move only along the vertical direction.

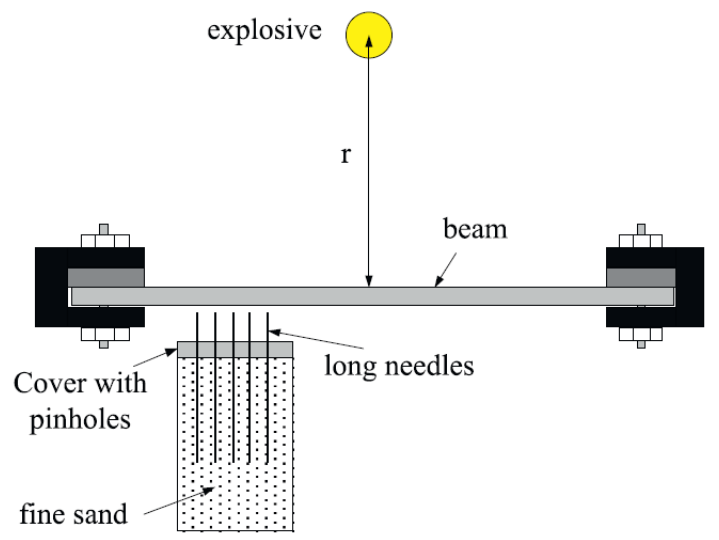

\begin{tabular}{|c|c|c|c|}
\hline Beam & $\begin{array}{c}\text { Dimension } \\
(\mathrm{mm})\end{array}$ & $\begin{array}{c}\text { TNT } \\
(\mathrm{Kg})\end{array}$ & $\begin{array}{c}\text { Standoff distance } \\
(\mathrm{m})\end{array}$ \\
\hline \multirow{2nnn}{*}{$100 \mathrm{X}-1$} & \multirow{2}{*}{$100 \mathrm{X} 1100$} & 0.36 & 0.4 \\
\cline { 1 - 1 }$B 2-2$ & 0.51 & 0.4 \\
\hline
\end{tabular}

Table 4. Experimental program (Zhang et al 2013)

\section{Numerical Modeling}

The volumetric finite element program "ABAQUS" was used to perform the nonlinear analysis of the reinforced concrete beams. The model is composed of two main parts: the concrete body that was modeled using a solid element, and steel reinforcement that was modeled as a rebar element. A Dynamic explicit analysis step was chosen for the case with a reasonable time step close to the experimental interaction time.

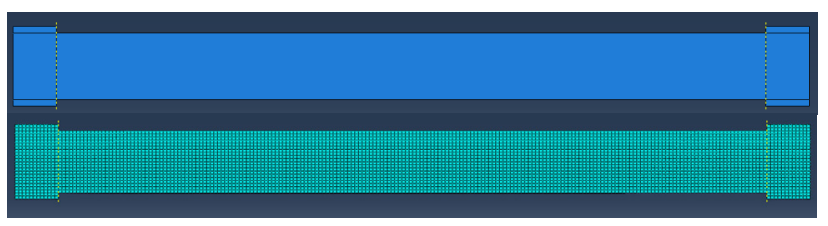

Figure 3. Finite Element Modeling of beam

The Concrete Damage Plasticity Model ${ }^{\mathbf{5}}$ will be used to define the behavior of concrete. This model works with static and dynamic load conditions. It was derived by Lubliner ${ }^{6}$ in 1989 and modified laster by Lee and Fenves ${ }^{7}$ in 1998. The model assumes that the concrete behave in a non-linear manner and different input parameters had to be assumed including: inelastic strain, cracking strain, stiffness degradation and recovery, and other parameters. There are many available methods that can model the reinforcing steel. For this simulation, the elasto-plastic behavior of reinforcing steel was considered, and a perfect bond between concrete and steel was assumed.

\section{Model Verification}

The model was calibrated until an acceptable error was reached. Two verifications were done for this process: comparing mid-span displacements and damage zone length. Table 5 and Figure 4 show the Mid-Span displacements for Beams B2-1 and B2-2. As shown the difference between experimental and numerical analysis is less than $10 \%$ (i.e. small). Therefore the verification is acceptable.

\begin{tabular}{|c|c|c|c|}
\hline \multirow{2}{*}{$\begin{array}{c}\text { Beam } \\
\text { Sample }\end{array}$} & \multicolumn{2}{|c|}{ Mid-Span Displacement $(\mathrm{mm})$} & \multirow{2}{*}{$\begin{array}{c}\text { Absolute } \\
\text { error } \%\end{array}$} \\
\cline { 2 - 3 } & Experimental & Numerical & 2.22 \\
\hline$B 2-1$ & 9 & 8.8 & 8.29 \\
\hline$B 2-2$ & 35 & 32.1 & \\
\hline
\end{tabular}

Table 5. Mid-Span Displacement for B2 samples

Figure 2. Experimental setup 


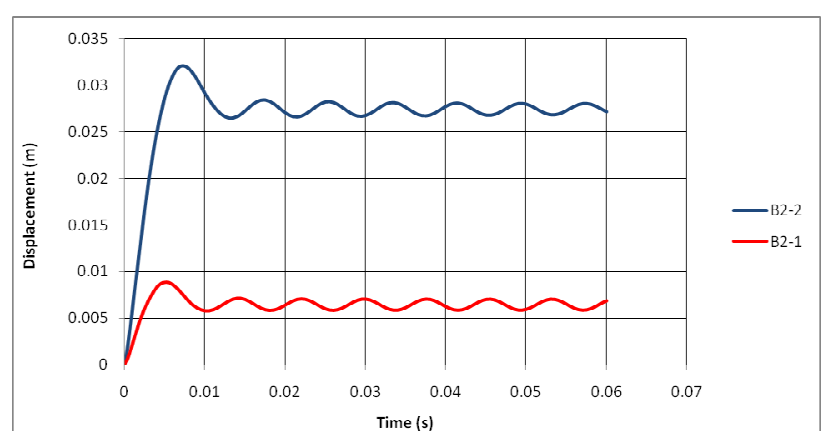

Figure 4. Time-Displacement Curves

\section{Iso-Damage Curve}

The damage analysis results for beam B2-2 are presented in this section. First the energy curves are shown in Figure 5, which represent the distribution of total work done with respect to denotation time.

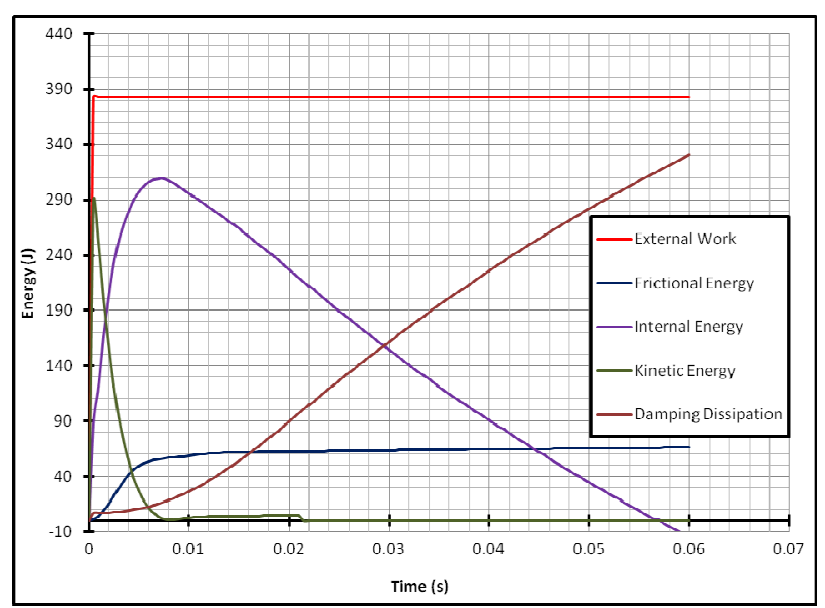

Figure 5. Distribution of Total work for beam B2-2

The Iso-Damage curve for B2-2 is shown below. A four combination of pressure and impulse were tested to check the validity of this curve as will be illustrated in Figure 6 and table 6.

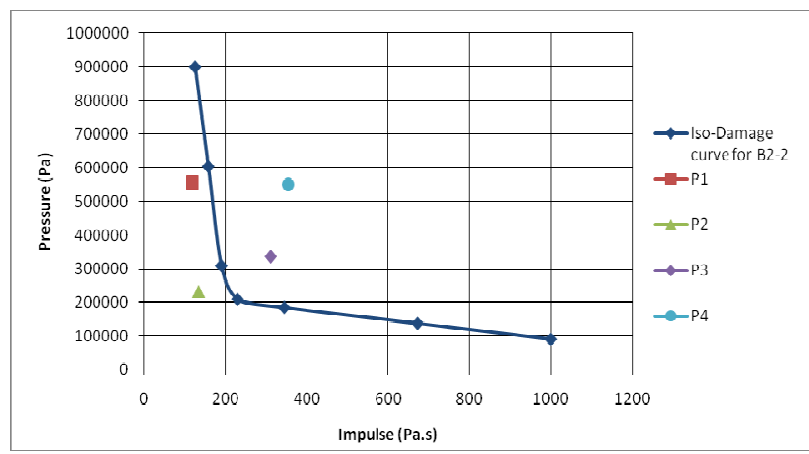

Figure 6. Iso-Damage curve for B2-2

\begin{tabular}{|c|c|c|c|c|}
\hline Point & $\begin{array}{c}\text { Stand-off } \\
\text { distance } \\
(\mathrm{m})\end{array}$ & $\begin{array}{c}\text { TNT mass } \\
(\mathrm{Kg})\end{array}$ & $\begin{array}{c}\text { Pressure } \\
(\mathrm{Pa})\end{array}$ & $\begin{array}{c}\text { Impulse } \\
\text { Pa.s }\end{array}$ \\
\hline P1 & 0.3 & 1 & 556000 & 119 \\
\hline P2 & 1 & 2 & 232000 & 134 \\
\hline P3 & 10 & 4 & 336000 & 311 \\
\hline P4 & 8 & 3 & 550000 & 345 \\
\hline
\end{tabular}

Table 6. (Pressure-Impulse) combinations

As shown, Both $\mathrm{P} 1$ and $\mathrm{P} 2$ will cause less damage compared to the real state of B2-2 (32.1 mm Mid-Span Displacement). On the other hand both P3 and P4 will cause more damage to B2-2. Figure 7 confirms this fact by plotting the Mid-span displacement for these four combinations compared to the real beam state B2-2.

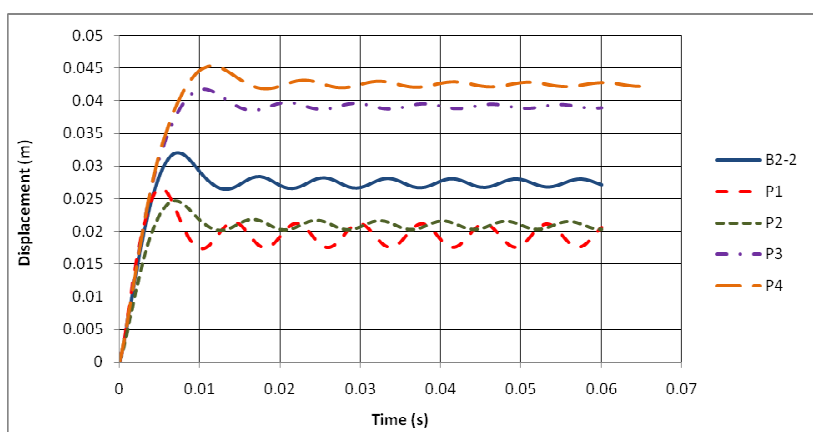

Figure 7. Mid-Span displacement compared to B2-2

\section{Conclusions}

The outcomes of this investigations lead to the following conclusions:

1- It is possible to form the Iso-Damage curve for any structural elements using Finite Element Program such as ABAQUS.

2- The extend of damage to objects or structures is a function of the both the quantity and distance of blast materials.

\section{Further Research}

The following points may be considered for further studies:

1- Derivation of Iso-Damage curve for different types of structural elements (columns, walls ...etc).

2- Derivation of Iso-Damage curves using single degree of freedom analysis.

3- The effect of reinforcement ratio and distribution on the damage capacity and Iso-damage curve behavior for structural elements.

4- The possible solutions to increase the range of safety for elements such as new materials. 


\section{Reference}

1. Gurney, R. W. The Initial Velocities of Fragments from Bombs, Shells, and Grenades, BRL-405. Ballistic Research Laboratory, Aberdeen, Maryland. USA. 1943.

2. Jarrett $D E$. Derivation of the British Blasting materials Safety Distances. Annals New York Academy of Sciences, 152, Article 1. 1968.

3. Scilly $N F$ and High $W G$. The blast effect of explosions. Loss prevention and safety promotion 5 . 1986

4. Duo Zhang, ShuJian Yao, Fangyun Lu, XuGuang Chen, Guhui Lin, Wei Wang \& Yuliang Lin. (July 5, 2013). Experimental study on scaling of RC beams under close-in blast loading. Retrieved December 7, 2015 from: http: // www.sciencedirect.com /science/ article/pii/ S1350630713002203.

5. Hibbitt, Karlsson, Sorensen, 2011, ABAQUS User's Manual, Pawtucket, 6th Edition.

6. Lublinear, J., Oliver, J., Oller, S., Onate, E., 1989. A plastic-damage model for concrete, Solids and Structures, Vol. 25, No. 3, pp. 299-326.

7. Lee, J., Fenves, G., 1998. Plastic-damage model for cyclic loading of concrete structure, Engineering Mechanics, Vol. 124, No. 8, pp. 892-900. 